\title{
PROFESSIONAL COMPETENCIES IN SHAPING THE ORGANIZATIONAL COMPETENCES OF POLISH EMERGENCY MEDICAL UNITS IN THE LIGHT OF SURVEY RESEARCH
}

\author{
Agnieszka KRAWCZYK-SOŁTYS \\ Opole University, Faculty of Economics; akrawczyk.soltys@uni.opole.pl, ORCID: 0000-0003-1575-3497
}

\begin{abstract}
Purpose: The aim of the article is to identify the current level of professional competencies and to determine the extent to which individual professional competencies affect the organizational competences of Emergency Medical Units in the areas of marketing (recognizing the patient's needs), quality (level of medical services) and logistics (provision of medical services in the right place and time).
\end{abstract}

Design/methodology/approach: The model of professional competencies of medical staff employed in Polish EMU establishes eight domains. To achieve superior organizational performance is very important to identify which set of professional competencies is required to gain their strategic goals. The research was carried out in 2018 in Emergency Medical Units in six voivodships. 135 respondents took part in the survey.

Findings: As a result of the research, it is determined that the highest level among the professional competencies presented in the model is characterized by transportation competencies. Among managerial competencies, the following have the greatest impact on the organizational competences of Emergency Medical Units: in the area of quality - transportation competencies, while in the areas of marketing and logistics - transportation, therapeutics and assessment and diagnostics competencies.

Practical implications: Nowadays health systems are being confronted with rapidly increasing demand generated by the COVID-19 outbreak. A well-organized and prepared health system has the capacity to maintain equitable access to essential service delivery throughout an emergency, limiting direct mortality and avoiding increased indirect mortality.

Originality/value: An integration professional competencies of medical personnel of Emergency Medical Units with its organizational competences especially relevant in pandemic time.

Keywords: Emergency Medical Units, organizational competences, professional competencies.

Category of the paper: research paper. 


\section{Introduction}

The predominant objective of Emergency Medical Units, correspondingly to the Polish health policy, is to provide patients with compelling healthcare by implementing an emergency medical service which takes into consideration the expectations and values of patients. The aim depends on suitable professional competencies of the personnel hired in these units, managerial competencies controlling these organizations, as well as managerial competences.

Contemporary medical entities operate in a very turbulent environment, and are shaped by the influence of factors which relate to both distal and near surroundings (mainly due to underfunding, lack of liquidation, performing a social mission resulting from the nature of these units, etc.). These factors contribute to an increase in the requirements for medical entities, including emergency medical units. They include, in particular: patient orientation and needs, high quality of medical services provided and the optimization of the functioning of these organizations within the budget. The knowledge and competences of the personnel employed in these organizations are therefore becoming increasingly important because more and more needs are identified to facilitate the transfer of research solutions to clinical and management practice and the development of policy and legal solutions in this field, which should ultimately translate into better satisfaction for the needs of patients, as well as increasing the competitiveness of these units (Krawczyk-Sołtys, 2018).

Nowadays health systems are being confronted with rapidly increasing demand generated by the COVID-19 outbreak. A well-organized and prepared health system has the capacity to maintain equitable access to essential service delivery throughout an emergency, limiting direct mortality and avoiding increased indirect mortality. Hence, there is so important to integrate professional competencies of medical personnel of Emergency Medical Units EMU with its organizational competences.

The issue of professional competencies was promoted by D. McClelland (Mc Clelland, 1973), one of the founders of the Hay McBer, who theorized that in the aspect of foreseeing the future efficiency of people's work, not their intelligence but instead their competencies should be examined.

The precursor of resource approach, E.T. Penrose (Penrose, 1959), was the leader in noticing organizational competences, stressing that in order to gain a competitive advantage, not only are the organization's resources crucial, but primarily - the skills to use them in processes.

Competency identification systems need to identify both - personal (professional and managerial) competencies and organizational competences (Boam, and Sparrow, 1992).

The competences of healthcare organizations may be acquired from different kinds of knowledge. Some of them rely on "know-how" - practical forms of knowledge obtained through incremental advancements to medical services and processes, another - on "know- 
why" - theoretical forms of comprehending that allows the creation of new kinds of services and processes. Different healthcare organizations competences come from diverse levels of activity: some are determined broadly from the capabilities of these entities to create and provide definite types of medical services, another is implied to come from the abilities to plan and organize resources in new and powerful ways, others mostly rely on the potential of managers to build up new strategies for creating organizational value.

This article focuses on the identification of common professional competencies of medical personnel within Emergency Medical Units (EMU), as well as the significantly shaped competences of such organizations in order to determine the extent to which individual professional competencies affect the organizational competences of these entities in the areas of marketing (recognizing the patient's needs), quality (the level of medical services) and logistics (a provision of medical services in the right place. The proposed lists of managerial and professional competencies were created and are based on the analysis of healthcare competencies models - the study of the literature - and the author of this papers observations of the analyzed entities.

The article assumes that competencies are a conglomerate of abilities consisting of: knowledge, education, experience, other predispositions and personality traits. These competencies are used and developed in the process of providing medical services in order to achieve results consistent with the strategic intentions of emergency medical units (KrawczykSołtys, 2018a).

\section{A model overview of professional competencies in health care}

Team for Research on Hospital Management "Avicenna" of the Jagiellonian University on the grounds of research established 13 competencies of medical staff, which were split into three classes of interpersonal and social competencies, i.e. threshold, desirable and expected competences: communication, defiance to stress, empathy, assertiveness, optimism, availability, responsibility, regularity, accuracy, openness, creativity, perseverance, willingness and catalyst to permanently boost knowledge and skills (Kęsy, 2013).

Threshold competencies comprise of communication skills. Furthermore, the ability to create a directive so as not to provoke the imbalance of information between the staff and the patient in an empathetic manner is crucial for medical workers. This group also consists of regularity (which is not only a ground for development at work, but also in the face of medical knowledge, permanent learning) and openness (aiming to reduce the distance between the patient and the staff). Competencies, practicality and promoting the achievement of duties for medical employees cover responsibility and assertiveness and concentrate on the skill to argue, explain the diagnosis and set up the treatment process, etc. Another advantageous competence 
is resistance to stress, optimism and accuracy. The continuing competencies are presented in the expected group, which are not crucially at the positions of medical employees, but undoubtedly boost the character of work.

R.M. Epstein and E.M. Hundert (Epstein, and Hundert, 2002) characterized the professional competencies of medical staff as the repeated and skillful use of communication, knowledge, professional skills, scientific understanding, emotions, qualities, and reflection in everyday practice for the benefits of the individual and the community being dealt with. Professional competencies are framed and based on a groundwork of elemental clinical skills, scientific knowledge, and principled advancement. They cover a cognitive role (acquiring and adopting knowledge), a centralizing function (accounting biomedical and psychosocial statistics when it comes to clinical reasoning), and principled function (the eagerness, patience, emotional awareness). Enumerated competencies are progressive, temporary, and context-vulnerable and are believed to rely on the mode of the mind. This comprehension of competencies is comparable to the thorough typology of competencies often quoted in the literature presented by G. Cheetham and G. Chivers (Cheetham, and Chivers, 1996, 1998): cognitive competencies, functional competencies, personal (behavioral) competencies, ethical competencies, and metacompetencies (applied with the possibility to deal with ambivalence).

Another proposition is five clusters of competencies for coordinated/integrated health services (Langings, and Borgermans, 2015):

1. patient advocacy - ability to promote patients' right to ensure the best quality of care and empowering patients to become active participants of their health;

2. effective communication - ability to establish quickly a rapport with patients and their family members in an empathetic and sensitive manner incorporating the patients' perceived and declared culture;

3. team work - ability to function effectively as a member of an inter-professional team which includes providers, patients and family members in a way that reflects an understanding of a team dynamics and group/team processes in building productive working relationships and that is focused on health outcomes;

4. people-centred care - ability to create conditions for providing coordinated/integrated services focused on the patients and their families' needs, values and preferences along with a continuum of care and over the life-course;

5. continuous learning - ability to demonstrate reflective practice, based on the best available evidence and to assess and continually improve the services delivered as an individual provider and as a member of an inter-professional team.

These provide a foundation for evaluating the performance of the medical staff. These clusters are fundamental to achieving care that is appropriate, evidence-based, personalized, population-focused, comprehensive, accessible, coordinated and continuous. 
A set of simple, core competencies is proposed that medical staff should possess:

- provide patient-centered care-identify, respect, and care about patients' differences, values, preferences, and expressed needs; relieve pain and suffering; coordinate continuous care; listen, inform clearly, communicate and educate patients; share decision making and management; continuously advocate disease prevention, wellness, and promotion of healthy lifestyles, including a focus on the health of the population;

- work in interdisciplinary teams - cooperate, collaborate, communicate, and integrate care in teams to ensure that the care is continuous and reliable;

- employ evidence-based practice - integrate best research with clinical expertise and patient values for optimum care, and participate in learning and research activities to a feasible extent;

- apply quality improvement-identify errors and hazards in care; understand and implement basic safety design principles, such as standardization and simplification; continually understand and measure quality of care in terms of structure, process, and outcomes in relation to patient and community needs; design and test interventions to change processes and systems of care, with the objective of improving quality;

- utilize informatics-communicate, manage knowledge, mitigate error, and support decision making using information technology.

Significant work undertaken by researchers and experts in this competency area reveals the specific skills required by today's medical staff to be more responsive to patient's needs (Halpern et al., 2001; Committee on Quality of Health Care in America, Institute of Medicine, 2001; Lewin et al., 2001; Mead and Bower, 2000; O'Neil, 1998; Stewart, 2001): share power and responsibility with patients and caregivers; communicate with patients in a shared and fully open manner; take into account patients' individuality, emotional needs, values, and life issues; implement strategies to reach out to those who can take care of themselves, include strategies of care which support the broader community, enhance prevention and promote health.

\section{An identification of the level of professional competencies in Emergency Medical Units and the degree of their impact on organizational competences - research results}

The research was conducted in the second and third quarters of 2018 in emergency medical units in the following regions: Śląskie, Mazowieckie, Opolskie, Warmińsko-Mazurskie, Lubelskie and Dolnośląskie. 135 respondents took part in the survey.

The selection of the research sample was random. The research sample included respondents from two regions characterized by the largest number of emergency medical teams (Mazowieckie - 193 and Śląskie - 116) and Warmińsko-Mazurskie region, where there is the 
largest indicator of the number of teams per 100,000 residents - 5.4 (average in Poland was 4) (Pomoc doraźna..., 2018).

According to the assumptions of healthcare marketing (Bober, Majchrzak-Lepczyk, 2015) in the sphere of marketing it is necessary to focus on the processes of providing medical services that determine the pro-quality needs of consumers and the implementation of tools and techniques shaping their repetitive quality. Among the key dimensions of the quality of services provided by emergency medical services, reference was made to substantive and psychosociological dimensions (Lisiecka-Biełanowicz, 2016). In the sphere of logistics, reference was mainly made to shaping, controlling and controlling supply and service processes implemented as part of actions aimed at saving people's health and life (Bartczak, 2015).

Respondents assessed the current level of professional competencies and the degree to which they affect organizational competencies in the areas of marketing (recognition of patient needs), quality (level of medical services rendered) and logistics (provision of medical services in the right place at the right time) (Krawczyk -Sołtys, 2018b).

The respondents were determined using a five-level Likert scale of the current level of professional competencies of medical staff then they were determined by the impact level of these competencies on organizational competences in three fields in five-level Likert scale marketing (perceiving patient's needs), quality (of implemented medical services) and logistics (arrangement of medical services both at the right time and place).

\subsection{An identification of the level of professional competencies in Emergency Medical Units}

The study presented that the highest rated professional competencies were Transportation Competencies $(4,30)$. The following were: firstly, preparing ambulance for service $(4,49)$, secondly, driving ambulance or emergency response vehicle $(4,23)$, thirdly, transferring patient to air ambulance $(4,14)$ fourthly, transporting patient in air ambulance $(3,94)$.

The next researched area were Therapeutics Competencies $(4,18)$. The results presented data in the following order of significance: preparing oxygen delivery devices $(4,54)$, delivering oxygen and administering manual ventilation $(4,44)$, utilizing ventilation equipment $(4,23)$, immobilizing actual and suspected fractures $(4,20)$, maintaining patency of upper airway and trachea $(4,10)$, administering medications $(4,07)$, providing basic care for soft tissue injuries $(4,05)$, implementing measures to maintain hemodynamic stability $(3,77)$.

Then, as far as the study is concerned the respondents referred to the level of Professional Responsibilities Competencies (4,11). The figures show as follows: functioning as a professional $(4,13)$, participating in continuing education and professional development $(3,77)$, possessing an understanding of the medicolegal aspects of the profession $(4,19)$, recognizing and complying with relevant Polish legislation $(4,01)$, functioning effectively in a team environment $(4,22)$, making decisions effectively $(4,10)$, managing scenes with actual or potential forensic implications $(4,34)$. 
In sequence, Assessment and Diagnostics Competencies have been established $(4,06)$. The results are presented as regards: conducting triage in a multiple-patient incident $(4,01)$, obtaining patient history $(4,08)$, conducting complete physical assessment demonstrating appropriate use of inspection $(3,92)$, palpation and percussion $(4,57)$, assessing vital signs, utilizing diagnostic tests $(3,74)$.

Another observation finds that respondents indicated Communication Competencies $(3,94)$. In regards to: practicing effective oral $(4,04)$ and written $(3,91)$ communication skills, practicing effective non-verbal communication skills $(3,84)$ and practicing effective interpersonal relations $(3,98)$.

The analysis of respondents in question pinpointed Communication Competencies $(3,94)$ : practicing effective oral $(4,04)$ and written $(3,91)$ communication skills, practicing effective non-verbal communication skills $(3,84)$ and practicing effective interpersonal relations $(3,98)$.

This paragraph presents the results of interpretation of respondents who pointed Integration Competencies $(3,86)$ : utilizing differential diagnosis skills, decision-making skills and psychomotor skills in providing care to patients $(3,85)$, providing care to meet the needs of unique patient groups $(3,83)$, conducting ongoing assessments and provide care $(3,89)$.

It is paramount to stress that according to the respondents opinion Health Promotion and Public Safety Competencies $(3,72)$ are of the lowest level. Therefore presenting the components present as follows: integrating professional practice into community care $(3,43)$, contributing to public safety through collaboration with other emergency response agencies $(4,09)$, participating in the management of a chemical, biological, radiological, nuclear and explosive incident $(3,66)$.

\subsection{An identification of the impact level of professional competencies on organizational competences of Emergency Medical Units in the area of marketing}

Examination of key points in this section highlights the highest rated professional competencies which were Transportation Competencies $(4,07)$. For the sake of clarity, preparing ambulance for service $(4,21)$, driving ambulance or emergency response vehicle $(4,14)$, transferring patient to air ambulance $(4,04)$ and transporting patient in air ambulance $(3,88)$.

In the next area as regards Therapeutics Competencies $(4,04)$ the following statistic results are presented: maintaining patency of upper airway and trachea $(3,95)$, preparing oxygen delivery devices $(4,26)$, delivering oxygen and administering manual ventilation $(4,22)$, utilizing ventilation equipment $(4,11)$, implementing measures to maintain hemodynamic stability $(3,76)$, providing basic care for soft tissue injuries $(4,01)$, immobilizing actual and suspected fractures $(4,08)$, administering medications $(3,94)$.

If one takes into consideration the importance of Assessment and Diagnostics Competencies $(4,04)$ : then the following data concerns: conducting triage in a multiple-patient incident $(4,06)$, obtaining patient history $(4,07)$, conducting complete physical assessment demonstrating 
appropriate use of inspection $(3,94)$, palpation and percussion $(4,32)$, assessing vital signs, utilizing diagnostic tests $(3,80)$.

Then the respondents pointed to the level of distinction regarding Professional Responsibilities Competencies $(3,95)$. As regards the numbers, findings concern: functioning as a professional $(4,16)$, participating in continuing education and professional development $(3,72)$, possessing an understanding of the medicolegal aspects of the profession $(3,95)$, recognizing and complying with relevant Polish legislation $(3,84)$, functioning effectively in a team environment $(4,06)$, making decisions effectively $(3,99)$, managing scenes with actual or potential forensic implications $(3,91)$.

Next, respondents enumerations indicated Communication Competencies (3,90). The figures show as follows: practicing effective oral $(3,94)$ and written $(3,67)$ communication skills, practicing effective non-verbal communication skills $(3,97)$ and practicing effective interpersonal relations $(4,03)$.

The analysis of respondents in question pinpointed Integration Competencies $(3,88)$. The results present the following: utilizing differential diagnosis skills, decision-making skills and psychomotor skills in providing care to patients $(3,90)$, providing care to meet the needs of unique patient groups $(3,85)$, conducting ongoing assessments and provide care $(3,89)$.

Then, as far as the study is concerned the respondents referred to the level of Health and Safety Competencies $(3,78)$ : maintaining good physical and mental health $(3,63)$, practicing safe lifting and moving techniques $(3,74)$ and creating and maintaining a safe work environment $(3,96)$.

In the last section of the analysis, the study reveals that of the lowest level - in respondents opinion - are Health Promotion and Public Safety Competencies $(3,75)$. In regards to: integrating professional practice into community care $(3,55)$, contributing to public safety through collaboration with other emergency response agencies $(4,00)$, participating in the management of a chemical, biological, radiological, nuclear and explosive incident $(3,71)$.

\subsection{An identification of the impact level of professional competencies on organizational competences of Emergency Medical Units in the area of quality}

This section presents the results of the highest rated professional competencies $(4,16)$ which were: Transportation Competencies, Therapeutics Competencies and Assessment and Diagnostics Competencies.

It is important to emphasise that among Transportation Competencies the following were pointed out: firstly - preparing ambulance for service $(4,46)$, secondly - driving ambulance or emergency response vehicle $(4,25)$, thirdly - transferring patient to air ambulance $(4,11)$ and fourthly - transporting patient in air ambulance $(3,83)$.

Amid Therapeutics Competencies it is important to emphasise such data: maintaining patency of upper airway and trachea $(4,15)$, preparing oxygen delivery devices $(4,37)$, delivering oxygen and administering manual ventilation $(4,24)$, utilizing ventilation equipment 
$(4,24)$, implementing measures to maintain hemodynamic stability $(3,90)$, providing basic care for soft tissue injuries $(4,04)$, immobilizing actual and suspected fractures $(4,20)$, administering medications $(4,12)$.

At this stage, the analysis focuses on Assessment and Diagnostics Competencies which were supported by: conducting triage in a multiple-patient incident $(4,22)$, obtaining patient history $(4,19)$, conducting complete physical assessment demonstrating appropriate use of inspection $(4,10)$, palpation and percussion $(4,47)$, assessing vital signs, utilizing diagnostic tests $(3,81)$.

Another respondents examination of key points in this section highlights Professional Responsibilities Competencies (4,13). The results are presented as regards: functioning as a professional $(4,21)$, participating in continuing education and professional development $(3,83)$, possessing an understanding of the medicolegal aspects of the profession $(4,18)$, recognizing and complying with relevant Polish legislation $(4,10)$, functioning effectively in a team environment $(4,29)$, making decisions effectively $(4,19)$, managing scenes with actual or potential forensic implications $(4,13)$.

The analysis of this part aims to present respondents indication to Communication Competencies $(4,09)$. They are as follows: practicing effective oral $(4,07)$ and written $(4,01)$ communication skills, practicing effective non-verbal communication skills $(4,10)$ and practicing effective interpersonal relations $(4,16)$.

On the basis of respondents observation, the level of Health and Safety Competencies was described $(3,98)$ : maintaining good physical and mental health $(3,72)$, practicing safe lifting and moving techniques $(4,00)$ and creating and maintaining a safe work environment $(4,21)$.

In sequence, the statistics describe respondents answers in relation to Integration Competencies $(3,94)$. The figures show as follows: utilizing differential diagnosis skills, decision-making skills and psychomotor skills in providing care to patients $(3,88)$, providing care to meet the needs of unique patient groups $(3,97)$, conducting ongoing assessments and provide care $(3,97)$.

All in all, according to respondents the lowest level refers to Health Promotion and Public Safety Competencies $(3,80)$. They concern: integrating professional practice into community care $(3,37)$, contributing to public safety through collaboration with other emergency response agencies $(4,17)$, participating in the management of a chemical, biological, radiological, nuclear and explosive incident $(3,86)$.

\subsection{An identification of the impact level of professional competencies on organizational competences of Emergency Medical Units in the area of logistic}

The data shown in this section points out that the highest rated professional competencies, is namely Transportation Competencies $(4,30)$. They are in order of significance as follows: preparing ambulance for service $(4,45)$, driving ambulance or emergency response vehicle 
$(4,37)$, transferring patient to air ambulance $(4,23)$ and transporting patient in air ambulance $(4,16)$.

For the sake of clarity it is essential to point out that respondents referred to the level of Professional Responsibilities Competencies $(3,93)$. They were enumerated as follows: functioning as a professional $(4,01)$, participating in continuing education and professional development $(3,56)$, possessing an understanding of the medicolegal aspects of the profession $(3,94)$, recognizing and complying with relevant Polish legislation $(3,88)$, functioning effectively in a team environment $(3,99)$, making decisions effectively $(4,05)$, managing scenes with actual or potential forensic implications $(4,04)$.

Next, the examination of key points in this paragraph concerns Assessment and Diagnostics Competencies $(3,92)$. Hence, the results are presented as follows: conducting triage in a multiple-patient incident $(4,11)$, obtaining patient history $(3,89)$, conducting complete physical assessment demonstrating appropriate use of inspection $(3,83)$, palpation and percussion $(4,15)$, assessing vital signs, utilizing diagnostic tests $(3,62)$.

As regards Therapeutics Competencies $(3,88)$ it is observed that they include: maintaining patency of upper airway and trachea $(3,88)$, preparing oxygen delivery devices $(4,05)$, delivering oxygen and administering manual ventilation $(3,98)$, utilizing ventilation equipment $(3,93)$, implementing measures to maintain hemodynamic stability $(3,65)$, providing basic care for soft tissue injuries $(3,74)$, immobilizing actual and suspected fractures $(3,96)$, administering medications $(3,82)$.

Then, the respondents determined the level of Health and Safety Competencies $(3,77)$. The content refers to: maintaining good physical and mental health $(3,59)$, practicing safe lifting and moving techniques $(3,78)$ and creating and maintaining a safe work environment $(3,95)$.

This section focuses on the respondents indication of Communication Competencies $(3,76)$. They are: practicing effective oral $(3,84)$ and written $(3,59)$ communication skills, practicing effective non-verbal communication skills $(3,74)$ and practicing effective interpersonal relations $(3,88)$.

In sequence, the analysis of respondents answers highlighted the influence of Integration Competencies $(3,74)$. In regard to: utilizing differential diagnosis skills, decision-making skills and psychomotor skills in providing care to patients $(3,69)$, providing care to meet the needs of unique patient groups $(3,79)$, conducting ongoing assessments and provide care $(3,73)$.

The analysis focused on, in the respondents opinion, the lowest level of Health Promotion and Public Safety Competencies $(3,62)$. This section enumerates: integrating professional practice into community care $(3,26)$, contributing to public safety through collaboration with other emergency response agencies $(3,94)$, participating in the management of a chemical, biological, radiological, nuclear and explosive incident $(3,66)$.

As a matter of fact, the most significantly shaping organizational competences of Emergency Medical Units in all areas were Transportation Competencies. They are as follows: in marketing area $(4,07)$, in quality area $(4,16)$ and in logistic area $(4,30)$. In quality area the 
same indications - 4,16 - have been obtained amongst both Assessment and Diagnostics Competencies and Therapeutics Competencies.

Then, the data shows that:

- in marketing area respondents distinguished in the order of significance: Assessment and Diagnostics Competencies and Therapeutics Competencies $(4,04)$, Professional Responsibilities Competencies (3,95), Communication Competencies (3,90), Integration Competencies $(3,88)$, Health and Safety Competencies $(3,78)$ and Health Promotion and Public Safety Competencies $(3,75)$;

- in quality area respondents highlighted the influence of the following: Professional Responsibilities Competencies (4,13), Communication Competencies (4,09), Health and Safety Competencies (3,98), Integration Competencies $(3,94)$ and Health Promotion and Public Safety Competencies $(3,80)$;

- in logistics area as far as the study is concerned the respondents referred to: Professional Responsibilities Competencies (3,93), Assessment and Diagnostics Competencies $(3,92)$, Therapeutics Competencies $(3,88)$, Health and Safety Competencies $(3,77)$, Communication Competencies (3,76), and Health Promotion and Public Safety Competencies $(3,62)$.

\section{Conclusions and Further Research}

The significance of competencies issues and their importance in the management of healthcare organizations, including emergency medical units, is widely emphasized in the literature on the subject. (Liang et al., 2018, Leggat et al., 2011; Bartram et al., 2012; Clark, Armit, 2010; Richtie, Yen, 2013). The importance of the impact of professional competencies on organizational competences in health care is also pointed out (Lustri, Miura, Takahashi, 2007; Yang et al., 2006; Wickramasinghe, De Zoyza, 2011).

The accomplishments of such organizations (on top of the systems and processes that determine them) stem from the bodies who are linked with the process, the competence they separately and together have to possess, and the behaviour they must employ (individually and interactively) to implement the process - their competencies (Krawczyk-Sołtys, 2019).

The specific understanding of competencies in services, mainly professional services (in general public named human based) which emergency medical services are a part of, is pinpointed by S.G. Hein and C.D. Riegel (Hein, and Riegel, 2012). Correspondingly to the final effect of empirical research J.A. Chapman and G. Lovell (Chapman, and Lovell, 2006) have stated that the competence groundwork in professional services inclines the key skills and approaches necessary to grant the service. 
Evidence demonstrates that attempts concentrated on merging medical personnel knowledge and skills to community needs means potential deficits and maldistribution of the medical personnel, escalates productivity, work comfort, enrollment and confinement and, in a long term, supports to enhance the quality of care. The process of combining their professional competencies to patient requirements engages a lot more than only attaining this personnel that has general knowledge and skills to perform more efficiently and effectively. To some extent it means making certain that the medical personnel is capable of implementing these knowledge and skills into practice i.e. build up competencies or to intensify organizational competences of medical units.

The examination of professional competencies of Medical Emergency Units employees is to regulate presently possessed and achievable by the staff competencies crucial for effective, and quality decent accomplishment of aims and responsibilities. The competence test ought to be executed with a clear indication and explanation of individual competencies components, principally: knowledge, skills and attitudes.

Amongst the most crucial defining the bottom line competences of Medical Emergency Units one can determine precursors competencies, for which the impetus of the acquisition process is the following the recent technologies and solutions used in the provision of emergency medical services and mainstream competencies regulated by observing the organization's needs.

Healthcare organizations with core competences can somewhat determine the environments (i.e. creating new opportunities) in which they act and challenge and that is the reason why they are more likely to gain aimed outcomes (Eden, Ackermann, 2010).

The issue of competencies and their importance in the management of healthcare organizations, including emergency medical units, is attracting an increasing interest. It is especially evident in pandemic time. Therefore, it seems necessary to conduct empirical and literature research in this area, which will enrich scientific knowledge, rationalize research methodology, as well as allow to formulate recommendations for practice.

\section{References}

1. Bartczak, K. (2015). Logistyka w systemie ratownictwa medycznego w Polsce. Logistyka, 5, pp. 7241-7249.

2. Bartram, T., Casimir, G., Djurkovic, N., Leggat, S., and Stanton, P. (2012). Do perceived high performance work systems influence the relationships between emotional labor, burnout and intention to leave? A study of Australian nurses. Journal of Advanced Nursing, 68(7), pp. 1567-1578. 
3. Boam, R., and Sparrow, P.R. (eds.) (1992). Designing and Achieving Competency. A Competency Based Approach to Developing People and Organizations. London: McGraw-Hill.

4. Bober, B., Majchrzak-Lepczyk, J. (2015). Rola oraz zadania marketingu w procesie świadczenia usług w szpitalach publicznych. Handel Wewnętrzny, 5(358), pp. 62-80.

5. Chapman, J.A., and Lovell, G. (2006). The competency model of hospitality service: Why it doesn't deliver. International Journal of Contemporary Hospitality Management, 18(1), pp. 78-88.

6. Cheetham, G., and Chivers, G. (1996). Towards a holistic model of professional competence. Journal of European Industrial Training, 20(5), pp. 20-30.

7. Cheetham G., and Chivers, G. (1998). The reflective (and competent) practitioner: a model of professional competence which seeks to harmonize the reflective practitioner and competence-based approaches. Journal of European Industrial Training, 22(7), pp. 267276.

8. Clark, J., and Armit, K. (2010). Leadership competency for doctors: a framework. Leadership in Health Services, 23(2), pp. 115-129.

9. Committee on Quality of Health Care in America, Institute of Medicine (2001). Crossing the Quality Chasm: A New Health System for the 21st Century. Washington, DC: National Academy Press.

10.Eden, C., and Ackermann, F. (2010). Competences, Distinctive Competences, and Core Competences. In: R. Sanchez, A. Heene (eds.), A Focused Issue on Identifying, Building and Linking Competences. Research in Competence-Based Management, 5. Bingley: Emerald Group Publishing Ltd.

11. Epstein, R.M., and Hundert, E. (2002). Defining and Assessing Professional Competence. JAMA, 287(2), pp. 226-235.

12.Halpern, R., Lee M.Y., Boulter P.R., and Phillips R.R. (2001). A synthesis of nine major reports on physicians competencies for the emerging practice environment. Academic Medicine, 76(6), pp. 606-15.

13. Hein, S.G., and Riegel, C.D. (2012). Human Resource and Organizational Management Content in the Hospitality Curriculum: How the Professionals View It. Journal of Human Resources in Hospitality \& Tourism, 11(2). pp. 165-181.

14. Kęsy, M. (2013). Kształtowanie kompetencji menedżerskich personelu medycznego w szpitalach. Kraków: Wydawnictwo Uniwersytetu Jagiellońskiego.

15. Krawczyk-Sołtys, A. (2018a). Modelowanie kompetencji w jednostkach ratownictwa medycznego - założenia wstępne. In: M. Tutko, M. Wronka-Pośpiech (eds.), Nauki o zarzadzaniu $w$ odmiennych kontekstach badawczych (pp. 105-116). Kraków: Wydawnictwo Uniwersytetu Jagiellońskiego. 
16. Krawczyk-Sołtys, A. (2018b). Personal Competencies Enhancing Organizational Competences Of Emergency Medical Units In Poland - Empirical Research. Conference Proceedings Of The 2nd International Scientific Conference Development And Administration Of Border Areas Of The Czech Republic And Poland Support For Sustainable Development, E. Ardielli (ed.). Ostrava, pp. 125-134.

17. Krawczyk-Sołtys, A. (2019). Professional and managerial competencies enhancing organizational competences of emergency medical units. Zeszyty Naukowe Politechniki Śląskiej, 136, pp. 305-322.

18. Langings, M., and Borgermans, L. (2015). Strengthening a competent health workforce for the provision of coordinated/integrated health services. Working Document. Copenhagen: World Health Organization.

19. Leggat, S.G., Balding, C., and Anderson, J.A. (2011). Empowering health-care managers in Australia: an action learning approach. Health Services Management Research, 24(4), pp. 196-202.

20. Liang, Z., Howard, P.F., Leggat, S., and Bartram, T. (2018). Development and validation of health service management competencies. Journal of Health Organization and Management, 32(2), pp. 157-175.

21.Lewin, S.A., Skea, Z.C., Entwistle, V., Zwarenstein, M., and Dick, J. (2001). Interventions for providers to promote a patient-centred approach in clinical consultations (Cochrane Review). Cochrane Database System Review, 4: CD003267.

22.Lisiecka-Biełanowicz, M. (2016). Zarzadzanie jakościa relacji w organizacjach ochrony zdrowia. Warszawa: Difin.

23. Lustri, D., Miura, I., and Takahashi, S. (2007). Knowledge Management Model: Practical Application for Competency Development. The Learning Organization, 14(2), pp. 186-202.

24. McClelland, D. (1973). Testing for Competence Rather Than for "Intelligence". American Psychologist, 28, pp. 1-14.

25. Mead, N., and Bower, P. (2000). Patient-centredness: A conceptual framework and review of the empirical literature. Social Science Medicine, 51(7), pp. 1087-110.

26. O'Neil, E.H. and the Pew Health Professions Commission (1998). Recreating health professional practice for a new century - The fourth report of the PEW health professions Commission. San Francisco, CA: Pew Health Professions Commission.

27. Penrose, E.T. (1959). The Theory of the Growth of the Firm. New York: John Wiley \& Sons.

28. Pomoc doraźna i ratownictwo medyczne (2018). Warszawa: Główny Urząd Statystyczny, https://stat.gov.pl, 20.01.2019. 
29. Ritchie, D., and Yen, M. (2013). Health services management development: what formal knowledge should support the skills and experience required? Australian Health Review, 37(2), pp. 189-193.

30.Stewart, M. (2001). Towards a global definition of patient centered care. British Medical Journal, 322(7284), pp. 444-45.

31. Wickramasinghe, V., and De Zoyza, N. (2011). Managerial competency requirements that enhance organizational competences: A study of a Sri Lanka telecom organization. The International Journal of Human Resource Management, 22(14), pp. 2981-3000.

32. Yang, B.C., Wu, B.E., Shu, P.G., and Yang, M.H. (2006). On establishing the core competency identifying model: A value-activity and process oriented approach. Industrial Management \& Data Systems, 106(1), pp. 60-80. 